\title{
EDITORIAL
}

\section{Pentecostalismo e Política no BRAsil}

De acordo com o censo demográfico oficial brasileiro, em 1872 os católicos eram 99,7\% da população. Cem anos depois, em 1970, ainda eram uma presença hegemônica com cerca de 92\%. Mas nas últimas décadas, profundas transformações ocorreram. No último censo de 2010, os católicos despencaram para cerca de 64\% da população. Na rota inversa apareceram os evangélicos, que em 1930 eram 1,86\% e em 2010 chegaram a 22\% da população, uma massa de mais de 42 milhões de pessoas. O crescimento desse relativamente novo grupo religioso foi impulsionado sobretudo pelos pentecostais, que representam quase 60\% dos evangélicos no país. O destaque é para as Assembleias de Deus com cerca de 15 milhões de membros, a maior denominação. Apesar de compartilhar o nome com as Assemblies of God norte-americanas, a brasileira é autônoma e tem traços próprios. Seu modelo de gestão é descentralizado, de tal forma que sua influência se dá mais em termos locais e regionais do que nacionais. Em termos políticos, isso significa que sua força se faz sentir mais em disputas para o legislativo, que são pleitos proporcionais, como no caso de vereadores e deputados, do que nas disputas majoritárias, como é o caso das eleições para o Executivo.

No entanto, foi justamente a eleição para a presidência da República a que mais chamou a atenção dos analistas para a atuação política do mundo pentecostal, ao se atribuir a vitória de Jair Bolsonaro ao suposto "voto pentecostal". Digo suposto, em primeiro lugar, porque nem os evangélicos nem os pentecostais podem ser tomados como se agissem em bloco. Isso é válido para as denominações e até para a bancada evangélica, que tem consensos mínimos. Há evangélicos e pentecostais com variadas orientações políticas, além da composição paradoxal que permite ser conservador em termos de costumes e ser liberal em assuntos econômicos e sociais. Essa incoerência, no entanto, é percebida nos demais grupos cristãos como resultado da sedimentação cultural que ocorreu nas terras brasileiras. Em segundo lugar, e derivado do primeiro, o conservadorismo brasileiro se pauta na defesa de uma sociedade com valores tradicionais em termos de moral e sexualidade (monogamia, heterossexualidade, questões sobre aborto, etc.), além de comportamento clientelista (interesses privados sobre o público), questões que são comuns aos demais grupos, perdendo, por não ser específico do 
pentecostal, sua capacidade de ser uma categoria analítica adequada para se estudar o grupo.

A figura de Bolsonaro tem sido associada aos pentecostais pela mídia e por alguns analistas, mas o próprio presidente deixa claro sua pertença ao catolicismo, indicando que seu aceno ao mundo evangélico se trata de uma estratégia política-eleitoral. A primeira dama, Michele Bolsonaro, é membro da Igreja Batista Atitude, uma igreja que é filiada à Convenção Batista Brasileira (CBB), o braço mais tradicional dos batistas, que expulsou da organização as igrejas batistas "renovadas".

O pr. Silas Malafaia é um tele-evangelista que apresenta um programa de TV "Vitória em Cristo" que está no ar a cerca de 30 anos. Já pertenceu a dois dos três principais grupos institucionais das Assembleias de Deus no Brasil, mas, há alguns anos, rompeu com a instituição e fundou a própria denominação, Assembleia de Deus Vitória em Cristo (ADVEC). Sua biografia está marcada por polêmicas. No entanto, como tem programa de TV em diferentes horários e emissoras, além de forte presença nas redes socais, Malafaia faz campanha política para vários candidatos, nem sempre religiosos. Apesar do fato de que políticos apoiados pelo tele-evangelista estiveram envolvidos em escândalos de corrupção nas últimas décadas, ele continua com uma força eleitoral muito forte, justamente pelas bandeiras conservadoras em termos de costumes. Como parte da corrida eleitoral, Bolsonaro buscou aliar-se a Malafaia. Essa aliança, como se pode perceber, não é por razões religiosas ou teológicas, mas, eleitorais e por afinidade em termos de conservadorismo.

No ano de 2016, justamente quando a presidenta Dilma Roussef enfrentava seu pedido de impeachment no Congresso Nacional, Bolsonaro, já antecipando a corrida presidencial, fez um gesto político importante de aceno em direção aos evangélicos do país. Dentro do rio Jordão em Israel, o católico Bolsonaro foi rebatizado pelo pastor da Assembleia de Deus, Everaldo Dias Pereira. Para o eleitorado médio evangélico, Bolsonaro havia se "convertido", gerando mais afinidade. Mas quando foi questionado por seu bispo católico, Bolsonaro negou que tivesse renegado a fé católica, alegando tratar-se unicamente de gesto simbólico e eleitoral, apesar de ser teologicamente controverso. Assim, o candidato permaneceu católico e assumiu uma identidade evangélico-pentecostal, em um hibridismo eleitoreiro astuto. 
O "Pastor Everaldo", líder do Partido Social Cristão (PSC), do qual Bolsonaro era filiado, havia sido candidato a presidente do Brasil nas eleições de 2014, mas seu desempenho foi pífio (780 mil votos, 0,75\% dos votos), mostrando que a pertença pentecostal (pastor da Assembleia de Deus Madureira) não foi capital eleitoral. O Pastor Everaldo contava com o apoio de outros evangélicos como o Dep. Federal Marco Feliciano (um dos mais votados pelo Estado de São Paulo) e o ex-governador do Rio de Janeiro, Anthony Garotinho. O mesmo se pode dizer da candidata Marina Silva, que nas duas últimas eleições presidenciais chegou ao terceiro lugar, sendo membro das Assembleias de Deus. Em 2014 ela obteve 22 milhões de votos (21\%) e em 2018 apenas 1 milhão de votos (1\%). Marina não tem histórico de envolvimento com corrupção. O que teria pesado? Sua pauta não era conservadora o suficiente para o público, seja católico ou evangélico, e não atendia nem à esquerda nem à direita brasileira.

Por outro lado, basta olhar para o primeiro escalão do governo ultraconservador de Jair Bolsonaro para perceber que o alarme sobre a atuação dos pentecostais perde mais força. O ministro da Casa Civil, Onyx Lorenzoni, é membro da igreja luterana. Para o sistema presidencialista brasileiro é o ministro mais importante, comparando-se à figura do primeiro-ministro dos sistemas parlamentaristas. O ministro da Justiça e Segurança Pública (que também é responsável por atribuições do extinto Ministério do Trabalho), Sergio Moro, é católico. O ministro da Advocacia Geral da União, André Luiz de Almeida Mendonça, é pastor presbiteriano. Dos vinte e dois ministros de Estado do atual governo apenas um é pentecostal, que é a ministra Damares Alves, do Ministério da Mulher, da Família e dos Direitos Humanos. Damares havia sido pastora da Igreja do Evangelho Quadrangular e atualmente é pastora da Igreja Batista Lagoinha (batista renovada).

No âmbito do Congresso Nacional, a chamada "bancada evangélica”, com diferentes denominações para além dos pentecostais, somou cerca de 90 deputados no Congresso atual, o que equivale a pouco mais de $17 \%$ das 513 cadeiras. Seja a figura do presidente, que é católico, seja o primeiro escalão do Executivo, que tem apenas um ministro pentecostal ou a atual configuração da Câmara dos Deputados, a presença pentecostal é menor do que se alardeia. No caso das eleições presidenciais de 2018, Bolsonaro obteve cerca de 58 milhões de votos, e, segundo o perfil religioso levantado pelo Instituto Datafolha sobre intenção de votos às vésperas do segundo turno, 21 milhões desses votos teriam sido dos evangélicos. Considerando que os pentecostais são 60\% dos evangélicos no Brasil segundo o Censo de 2010, relevando as imprecisões desse cálculo, o total aproximado seria de 13 
milhões de votos. O voto católico no mesmo candidato teria sido mais do que o dobro dos pentecostais, cerca de 30 milhões, e representa $51 \%$ dos votos válidos. A questão que passa despercebida aqui é que sem o voto católico o Bolsonaro jamais teria sido eleito.

A participação política dos pentecostais é muito recente no cenário brasileiro, basicamente a partir de meados de 1980, e os problemas eleitorais envolvendo autoritarismo e políticas ultraconservadoras estiveram presentes desde o início da jovem República, de tal modo que esse grupo não é o foco do problema. Há os que veem a participação organizada dos pentecostais como um risco à democracia e há os que percebem essa atuação como um amadurecimento da participação social. A primeira suposição é muito questionável. A segunda, precisa ser analisada com mais atenção, pois para ser um jogo democrático, os agentes precisam efetivamente respeitar a diversidade e a pluralidade, isto é, reconhecer o lugar do outro e, juntos, construírem a nação. Por isso não defendo aqui acriticamente o conteúdo da atuação pentecostal, mas seu lugar como agente social e político.

Por outro lado, a natureza da participação dos diferentes grupos na política é mais importante do que se há ou não participação. A fase inicial de "não-participação" pode ter variadas razões. É possível que os grupos não se envolvessem porque estavam demasiadamente ocupados com questões espiritualizantes e não queriam enfrentar questões sociais e políticas. Ou, esses grupos se sentiam representados pelas posições políticas conservadoras do status quo e não considerassem necessário reforçá-las. Ou ainda, como grupos minoritários e segregados, comportavam-se como uma seita do ponto de vista sociológico, sem pretensões de ser igreja e ter mais envolvimento público. Da mesma forma, a mudança de atitude para uma participação mais ativa pode ter ocorrido justamente pelas mudanças sociais e culturais percebidas na sociedade, justificando a disputa pela manutenção dos costumes tradicionais. Essa mudança estaria mais atrelada à ameaça contra a sociedade tradicional e à percepção de que isso deveria ser defendido do que a uma trivial participação como resultante de mero crescimento numérico. $O$ fato dos evangélicos e pentecostais terem se unido ao catolicismo, um de seus arqui-inimigos históricos no país, para juntos elegerem um presidente católico é sintomático. A pauta ultraconservadora em temas de costume teria sido o principal elemento de coalisão entre os cristãos, apesar de que em termos econômicos e sociais eles estejam mais vinculados ao pensamento liberal. 
Para não cair em generalizações ou em reprodução acrítica da literatura sobre o tema é importante fomentar pesquisas empíricas sobre o fenômeno pentecostal em sua dinâmica pública. As Ciências das Religiões e a Teologia têm aqui uma grande contribuição a fazer para a sociedade. A Revista Interações fez muito bem em dedicar um dossiê para acolher pesquisas sobre essa importante questão.

\section{David Mesquiati de Oliveira}

Doutor em Teologia pela PUC Rio. Pósdoutor pelo Seminário Teológico de Princeton EUA. Atualmente, é professor do PPGCR-UNIDA (Faculdade Unida de Vitória) e coordenador da RELEP Brasil (Rede Latino-americana de Estudos Pentecostais) 